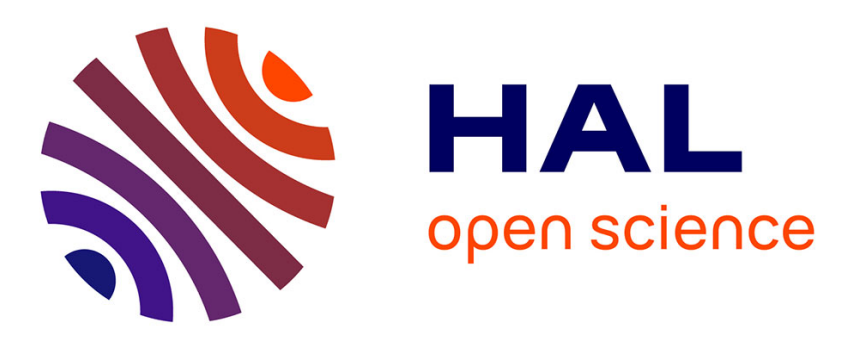

\title{
Optical properties of InAs/InP surface layers formed during the arsenic stabilization process
}

A. Tabata, T. Benyatou, Gérard Guillot, Michel Gendry, Guy Hollinger, P. Viktorovitch

\section{- To cite this version:}

A. Tabata, T. Benyatou, Gérard Guillot, Michel Gendry, Guy Hollinger, et al.. Optical properties of InAs/InP surface layers formed during the arsenic stabilization process. Journal of Vacuum Science \& Technology B Microelectronics and Nanometer Structures, 1994, 12 (4), pp.2299. 10.1116/1.587756 . hal-02200441

\section{HAL Id: hal-02200441 \\ https://hal.science/hal-02200441}

Submitted on 5 Apr 2020

HAL is a multi-disciplinary open access archive for the deposit and dissemination of scientific research documents, whether they are published or not. The documents may come from teaching and research institutions in France or abroad, or from public or private research centers.
L'archive ouverte pluridisciplinaire HAL, est destinée au dépôt et à la diffusion de documents scientifiques de niveau recherche, publiés ou non, émanant des établissements d'enseignement et de recherche français ou étrangers, des laboratoires publics ou privés. 


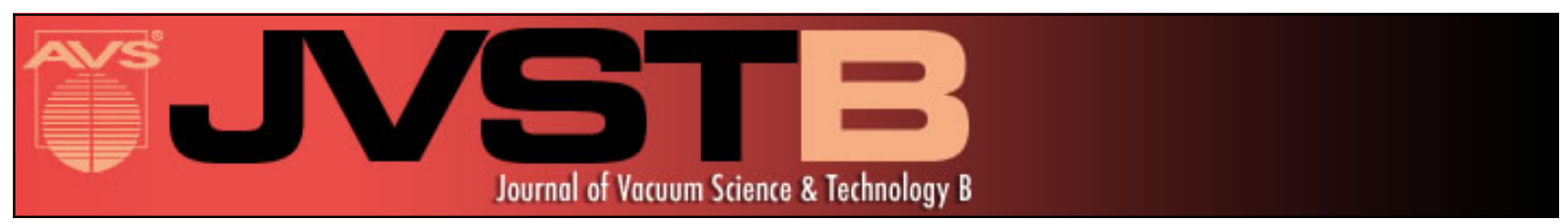

Optical properties of InAs/InP surface layers formed during the arsenic stabilization process

A. Tabata, T. Benyattou, G. Guillot, M. Gendry, G. Hollinger, and P. Viktorovitch

Citation: Journal of Vacuum Science \& Technology B 12, 2299 (1994); doi: 10.1116/1.587756

View online: http://dx.doi.org/10.1116/1.587756

View Table of Contents: http://scitation.aip.org/content/avs/journal/jvstb/12/4?ver=pdfcov

Published by the AVS: Science \& Technology of Materials, Interfaces, and Processing

\section{Articles you may be interested in}

Atomistic pseudopotential theory of optical properties of exciton complexes in InAs/lnP quantum dots Appl. Phys. Lett. 99, 231106 (2011); 10.1063/1.3669507

Optical properties of submonolayer InAs/lnP quantum dots on vicinal surfaces

J. Appl. Phys. 86, 6789 (1999); 10.1063/1.371728

On the optical properties of InAs/InP systems: The role of two-dimensional structures and three-dimensional islands

Appl. Phys. Lett. 72, 1015 (1998); 10.1063/1.120951

Optical properties of InAs/InP strained single quantum wells grown by organometallic vaporphase epitaxy J. Appl. Phys. 70, 405 (1991); 10.1063/1.350289

Structural and chemical properties of InAs layers grown on $\ln P(100)$ surfaces by arsenic stabilization J. Vac. Sci. Technol. B 8, 832 (1990); 10.1116/1.584974

Contact Hiden Analytical for further detalls:

w www.HidenAnalytical.com E info@hiden.co.uk

CLICK TO VIEW our product catalogue

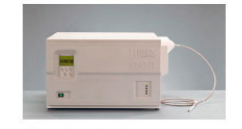

Gas Analysis

dynamic measurement of reaction gas streams

, catalysis and thermal analysis

- molecular beam studies

dissolved species probes

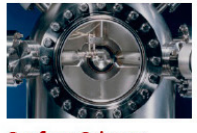

Surface Science

, UHV TPD
, SIMS

, plasma source characterization

elemental detection in ion beam etch

'elementamagn
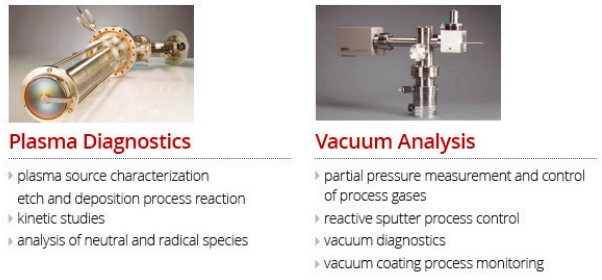


\section{Optical properties of InAs/InP surface layers formed during the arsenic stabilization process}

A. Tabata, T. Benyattou, and G. Guillot

Laboratoire de Physique de la Matière (URA CNRS 358). INSA de Lyon, 20 avenue Albert Einstein, 69621 Villeurbanne Cedex, France

M. Gendry, G. Hollinger, and P. Viktorovitch

Laboratoire d'Electronique Automatique et Mesures Electriques (URA CNRS 848), Ecole Centrale de Lyon. 36 avenue Guy de Collongue, 69131 Ecully Cedex, France

(Received 13 May 1993; accepted 6 May 1994)

Optical characterization has been performed on the InAs/InP surface layer in order to study the arsenic (As) stabilization process of InP. The InAs layers are formed by the simple exchange of phosphorus (P) from the InP surface substrate by arsenic. Samples prepared under arsenic overpressure in the temperature range $450-600^{\circ} \mathrm{C}$ have been examined. Luminescence from the InAs layer which acts as a surface quantum well has been detected. We have compared this emission with theoretical calculations and reasonable agreement was observed. Moreover, we have determined that when the arsenic stabilization temperature increases the InAs thickness increases as a consequence of P-As exchange and that after the replacement of the five first top monolayers this exchange seems to stop. We explain this result in terms of the shield effect of the InAs overlayers which efficiently cap the InP substrate against further $P$ evaporation and the restoration of surface structural order which limits any other phosphorus exodiffusion. Comparing our results with those of $\mathrm{x}$-ray photoelectron spectroscopy measurements we have concluded that on samples treated at high temperatures, three-dimensional InAs islands are formed.

\section{INTRODUCTION}

Conventional molecular beam epitaxy (MBE) consists essentially in condensation of a molecular or atomic flux obtained by evaporation of solid source, on a monocrystalline substrate. The growth of InGaAs and InAlAs by MBE requires a clean and well-ordered InP substrate surface. The main problem is to eliminate a thin native oxide layer without degradation of the surface. Generally, a wellreconstructed InP substrate surface can be obtained by thermal cleaning at $\sim 500^{\circ} \mathrm{C}$ under phosphorus ${ }^{1}(\mathrm{P})$ or arsenic ${ }^{2.3}$ (As) overpressure, which leads to a P- or an As-stabilized surface, respectively. There is no $P$ source available in most solid source MBE equipments and arsenic stabilization has been shown to be a good procedure to clean InP substrates. preserving both surface morphology and chemical stoichiometry. ${ }^{2.3}$ However, this treatment induces the formation of a thin and pseudomorphic InAs surface layer. ${ }^{4}$ At temperatures of the order of $500-540{ }^{\circ} \mathrm{C}$ not only the oxide desorption occurs but also a loss of phosphorus from the surface is induced by thermal desorption. ${ }^{2}$ Under vacuum. In droplets can be formed on the InP substrate surface; however, under As overpressure the desorbed $P$ is immediately replaced by As, forming then the InAs overlayer. ${ }^{3.4}$ Arsenic stabilization has also been used as a passivation process of InP surfaces for the fabrication of metal-insulatorsemiconductor (MIS) structures. ${ }^{5.6}$

The passivation of InP and the MBE growth of semiconductor layers on InP involve a number of technological steps, including substrate pregrowth treatments, which appear to be critical. In this respect there is a need for a detailed knowl- edge of the physico-chemical and structural properties of the pseudomorphic InAs layer, as a function of the process parameters in relation to its electronic properties. In this framework, we present a study of optical properties of arsenicstabilized InP(001) surfaces based on low-temperature (5 K) photoluminescence (PL) measurements.

\section{SAMPLE PREPARATION}

Samples have been prepared in a Riber 2300 MBE reactor. The substrates were $\mathrm{InP},(001)$ oriented, $n$-type nonintentionally doped $\left(10^{16} \mathrm{~cm}^{-3}\right)$ wafers of "ready to use" quality from Sumitomo. A thermocouple and an infrared pyrometer were used to measure the sample temperature. The pyrometer was calibrated by directly observing the melting of an InSb crystal mounted on a molyblock with In solder. Prior to loading in the MBE chamber, the $\operatorname{InP}(001)$ substrates were chemically etched using about $10 \mathrm{cc}$ of an HF-ethanol (1:10) solution using a spinning technique. ${ }^{6}$ Then, the substrates were outgassed in an ultrahigh vacuum chamber at a temperature of $300^{\circ} \mathrm{C}$. The arsenic stabilization was done by heating the $\mathrm{InP}$ substrate in the $450-600^{\circ} \mathrm{C}$ temperature range under $1.5 \times 10^{-5}$ Torr of arsenic pressure. The duration of the annealing treatment varied from 2 to $10 \mathrm{~min}$. After the treatment the arsenic shutter was closed when the substrate temperature reached $300^{\circ} \mathrm{C}$. To prevent any remaining arsenic chemisorption, a final annealing treatment was performed under vacuum for each As-stabilized InP sample. The surface morphology and the surface reconstruction of the $\operatorname{InP}$ substrates were monitored by $10 \mathrm{keV}$ reflected high-energy electron diffraction (RHEED) and the chemical composition 
TaBle I. Characteristics of the various samples studied. $T_{3}$ is the temperature at which the arsenic stabilization has been done, ML is the number of InAs equivalent monolayers deduced by XPS measurements, $t$, is the keeping time to the annealing temperature.

\begin{tabular}{lcccc}
\hline Sample & $\begin{array}{c}T \\
\left({ }^{\circ} \mathrm{C}\right)\end{array}$ & $\begin{array}{c}t_{5} \\
(\mathrm{~min})\end{array}$ & $\begin{array}{c}\mathrm{ML} \\
(\mathrm{XPS})\end{array}$ & $\begin{array}{c}\text { Surface } \\
\text { reconstruction }\end{array}$ \\
\hline P2094 & 600 & 2 & & $4 \times 1$ \\
P252 & 575 & 0.5 & $2.60 \pm 0.2$ & $4 \times 1$ \\
P204 & 570 & 2 & $2.60 \pm 0.2$ & $4 \times 1$ \\
P253 & 550 & 10 & $1.65 \pm 0.2$ & $2 \times 1$ \\
P210 & 500 & 10 & $1.50 \pm 0.2$ & $2 \times 1$ \\
P254 & 450 & 10 & $1.25 \pm 0.2$ & $\cdots$ \\
P208 & 450 & 4 & $1.25 \pm 0.2$ & $\cdots$ \\
P207 & 525 & 2 & & \\
P203 & 500 & 10 & & \\
\hline
\end{tabular}

"No XPS measurement has been done.

${ }^{\text {hi }}$ Reference samples thermally treated in vacuum without arsenic overpressure.

of the InAs/InP surface layer was probed with highresolution $\mathrm{x}$-ray photoelectron spectroscopy (XPS). The RHEED and XPS results were already published elsewhere ${ }^{3}$ and will not be discussed here in detail. The characteristics of the various samples studied are listed in Table I. The average thickness of the InAs layers was determined by XPS. Two InP reference samples were also prepared: they were just annealed under vacuum at two different temperatures. The characteristics of these samples are also given in Table I.

\section{RESULTS AND DISCUSSION}

In Fig. 1 we present $5 \mathrm{~K}$ PL measurements for samples annealed under arsenic at $550,570,575$, and $600{ }^{\circ} \mathrm{C}$ which correspond to an average InAs thickness ranging from 1 to 3 monolayers (ML). At low substrate annealing temperature $\left(T_{s}\right)$ the PL spectrum consists of a main emission with a linewidth of about $150 \mathrm{meV}$. As $T_{s}$ is increased, the spectrum broadens being now formed by two or three mixed emissions, and finally, at higher $T_{s}$ the spectrum consists of a

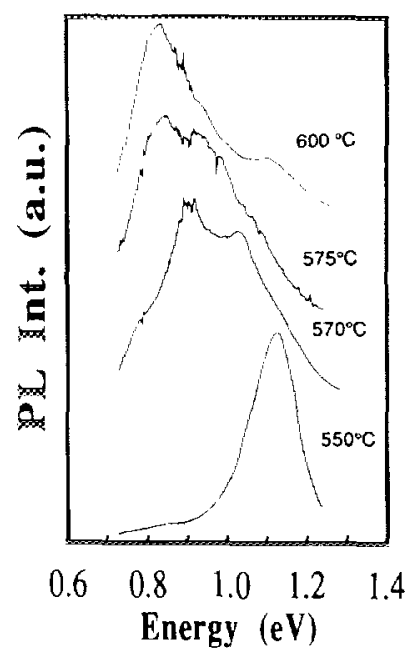

FIG. 1. Low-temperature photoluminescence spectra of arsenic-stabilized samples. The structures around $0.95 \mathrm{eV}$ are due to air absorption.

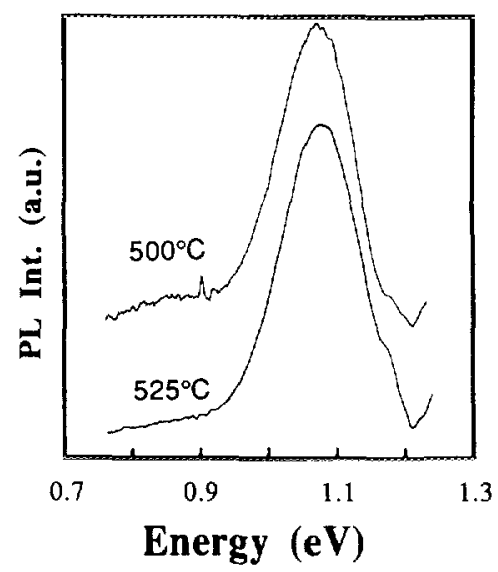

FIG. 2. Low-temperature PL spectra of the InP reference samples, thermally treated in vacuum without As overpressure.

main emission with a shoulder at the high-energy side. We will ascribe (see below) this emission to transitions related to radiative recombinations in the InAs surface layers.

PL results for the InP reference samples, without As treatment, are presented in Fig. 2. A defect band at $1.08 \mathrm{eV}$ is clearly observed and also a less important band at $0.85 \mathrm{eV}$. At the present time, the precise origin of these two emissions is not completely clear. As a possible origin, Yu has proposed that the $1.08 \mathrm{eV}$ deep level could be related to a complex involving a phosphorus vacancy bound to iron. ${ }^{7}$ However, in our study the substrates are $n$-type nonintentionally doped and the iron concentration should be very small. Temkin et al. have proposed for the same level a complex involving a di-vacancy of indium and phosphorus. ${ }^{8}$ For the emission at $0.85 \mathrm{eV}$, Rao et al have proposed as a possible origin a complex involving a phosphorus vacancy bound to some acceptor impurity. ${ }^{9}$

In Fig. 3, we present PL results for the samples P209, P252. P204, and P253 after chemical etching of the first $50 \AA$ near the surface, including the 1-3 InAs monolayers. This was done in order to check whether or not the emissions reported in Fig. 1 really come from the InAs surface layers. Great differences can be seen when comparing spectra of Fig. 1 (nonetched samples) and Fig. 3. Moreover, after etching identical results to reference samples (Fig. 2) are obtained. This means that after etching samples present transitions just related to deep defect emissions.

From the different results described above, we attribute the PL emissions presented in Fig. 1 as being due to the $\operatorname{InAs}$ surface layer. This is based on the following arguments: (i) PL emissions for As-stabilized samples do not correspond in energy to the "defect" bands observed for the reference samples (Fig. 2). (ii) the PL emissions disappear after $50 \AA$ etching (Fig. 3), and (iii) their maximum shifts to lower energies when increasing the arsenic stabilization temperature. We interpret the luminescence of this layer as follow: as InAs has a smaller band gap than InP $(0.42$ and $1.42 \mathrm{eV}$ at 0 $\mathrm{K}$, respectively), ${ }^{10}$ the InAs surface layer can form a quantum well bounded on one side by a monolayer oxide (and vacuum) and on the other side, by the InP substrate. ${ }^{11}$ Under 


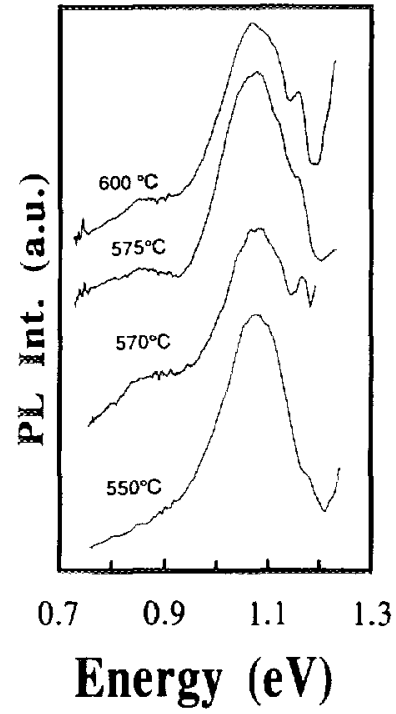

Fig. 3. Low-temperature spectra of As-stabilized samples with about the first $50 \AA$ near the surface chemically etched in order to remove the InAs layers.

these conditions, the photocreated carriers are confined in the InAs well and can thus recombine. For surface quantum wells, the main problem in achieving a high radiative efficiency is the existence of nonradiative transitions involving interface and surface states. Experimentally, light emission is observed thanks to the high density of carriers confined in the quantum well which can saturate these states. The presence of dislocations at the InAs/InP interface is another potential problem which can hinder a high light efficiency. These dislocations can act as carrier traps and kill radiative recombinations. Dislocations are associated to the high degree of lattice mismatch between InP and InAs (3.2\%). However, as the InAs average layer thickness (measured by XPS) is less than 3 monolayers, which is smaller than the critical thickness $\left(t_{c}\right)$ for the formation of defects such as dislocations found by Schneider and Wessels $\left(t_{c}=5 \mathrm{ML}\right)$ for InAs InP single quantum wells grown by metal-organic vapor phase epitaxy ${ }^{12}$ and by Hollinger et al. $\left(t_{c}=6-7 \mathrm{ML}\right)$ for InAs epitaxial layer grown on InP substrate by $\mathrm{MBE}^{13}{ }^{13}$ we believe that dislocations (if they exist) are not present in large concentration. So, we associate the observed PL emissions of the Fig. I to radiative transitions in the InAs surface quantum well between the fundamental electron $\left(E_{1}\right)$ and heavy hole $\left(H_{1}\right)$ subbands.

In order to determine more precisely the different transitions shown in Fig. 1, we have fitted each spectrum with Gaussian lines. A Gaussian form has been chosen because it well describes an excitonic emission. ${ }^{14}$ In quantum wells excitonic line shape has a Gaussian character due to the statistical (Gaussian) distribution of the interface roughness. ${ }^{15}$ So, for sample P253 $\left(T_{s}=550{ }^{\circ} \mathrm{C}\right)$, characterized by a $2 \times 1$ Asstabilized surface observed by RHEED and an InAs thickness of 1.65 ML deduced by XPS, we have found that the best fit is obtained with a sum of three Gaussians which are ascribed to emissions related to $2 \mathrm{ML}$ (most intense) and 3
TABLE II. Values of energy emission (eV)/linewidth (meV) obtained by fit of the spectra of Fig. 1.

\begin{tabular}{cccccc}
\hline \hline Sample & $2 \mathrm{ML}$ & $3 \mathrm{ML}$ & $4 \mathrm{ML}$ & $5 \mathrm{ML}$ & Defect line \\
\hline $\mathrm{P} 253$ & $1.13 / 125$ & $1.03 / 130$ & & & $0.86 / 1.72$ \\
$\mathrm{P} 204$ & $1.10 / 205$ & $1.00 / 150$ & $0.90 / 95$ & $0.80 / 110$ & \\
P252 & $1.13 / 135$ & $1.01 / 150$ & $0.96 / 110$ & $0.83 / 135$ & \\
P209 & & & $0.94 / 105$ & $0.83 / 130$ & $1.08 / 182$ \\
\hline
\end{tabular}

ML of InAs. The third Gaussian at $0.86 \mathrm{eV}$ is ascribed to the deep defect emission as already commented. For sample P204 $\left(T_{s}=570^{\circ} \mathrm{C}\right)$, characterized by a $4 \times 1$ In-stabilized surface and an XPS InAs thickness of $2.6 \mathrm{ML}$, the best fit is obtained with four Gaussians corresponding to emissions of 2, 3, 4 (most intense), and $5 \mathrm{ML}$. For sample P252 $\left(T_{s}=575^{\circ} \mathrm{C}\right)$ corresponding to an XPS thickness of $2.6 \mathrm{ML}$ and a $4 \times 1$ In-stabilized surface, the best fit is also obtained with four Gaussians $(2,3,4$, and $5 \mathrm{ML}$ ), the $5 \mathrm{ML}$ one being the most intense. Finally, for sample P209 $\left(T_{s}=600^{\circ} \mathrm{C}\right)$, three Gaussians have been used which correspond to emission of 4 and $5 \mathrm{ML}$ (the $5 \mathrm{ML}$ one being the most intense) and to an emission due to a deep defect emission at $1.08 \mathrm{eV}$. XPS measurements have not been performed for this last sample. The maximum energy and the full width at half maximum (FWHM) of the Gaussians used in the fits are presented in Table II. It is worth noting that we have not detected defect bands in the majority of arsenic-treated samples due to the weak intensity of those which were hidden by the InAs emission.

In Fig. 4 we show the result of the fit for sample P204. The solid line is the experimental curve, the dashed lines correspond to fitted Gaussians for well thicknesses of 2, 3, 4, and $5 \mathrm{ML}$, and the dotted line, the sum of these Gaussians. We can see the excellent agreement with the experimental results. The same agreement between experimental and fitted curves was found for the other samples.

Through the above results we have deduced that (i) as the annealing temperature increases the strongest emission line moves to lower energy, meaning that the thickness of the InAs layer increases and that $\mathrm{P}$-As exchange takes place more and more deeply as the temperature increases, (ii) when the surface stabilization changes from As- to In-stabilized

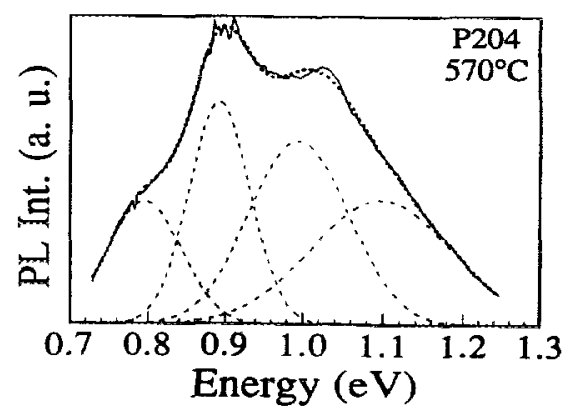

FIG. 4. Fitting result for the PL spectrum of sample P204 resolved into four Gaussian components. Solid line is the experimental result, dashed lines correspond to the fitted Gaussians, and dotted one the sum of these Gaussians. 
surface a remarkable change in As penetration depth is observed (from 3 to $5 \mathrm{ML}$ ), and (iii) after the replacement of the first five top layers the P-As exchange process seems to stop, as will be discussed below. In Fig. I, we can observe that for an As-stabilized InP surface prepared at $T_{s}=550^{\circ} \mathrm{C}$ the penetration of arsenic atoms in the InP substrate results in the formation of $3 \mathrm{ML}$ InAs layer. When increasing the temperature by $20^{\circ} \mathrm{C}$ leading to an In-stabilized InP surface, a small quantity of arsenic atoms penetrates up to $5 \mathrm{ML}$ (small hump on the PL spectrum). When increasing now no more than $5{ }^{\circ} \mathrm{C}\left(T_{s}=575^{\circ} \mathrm{C}\right)$, more and more arsenic atoms penetrate up to $5 \mathrm{ML}$ as can be observed by the increase of $\mathrm{PL}$ intensity related to the $5 \mathrm{ML}$ well. At $T_{\mathrm{s}}=600{ }^{\circ} \mathrm{C}$ (which means an increase of $25^{\circ} \mathrm{C}$ ) the $5 \mathrm{ML}$ related emission is now the main one, but no emission related to well with more than $5 \mathrm{ML}$ thickness is detected. The exchange between As and $P$ seems to be stabilized after the replacement of the five first top layers. We explain this observation in terms of (i) a shield effect of the InAs overlayers which efficiently cap the InP substrate against further $\mathbf{P}$ evaporation and (ii) stabilization of the surface by restoration of the structural order which limits the exo-diffusion of phosphorus elements.

XPS studies ${ }^{3}$ of the As $2 p$ and P $2 p$ core-level regions have indicated that for samples prepared at temperatures lower than $550^{\circ} \mathrm{C}$, arsenic is present within at least the first two top layers while on the sample prepared at $T_{s}=575^{\circ} \mathrm{C}$ arsenic is present in at least the first three top layers and probably in the fourth one. However, it was not possible to answer the question whether or not some arsenic atoms have penetrated more deeply in the InP substrate. ${ }^{3}$ Our results have revealed that for the sample prepared at $T_{s}=550^{\circ} \mathrm{C}$ arsenic atoms are not only present in the first two layers but also in the third one (in small concentration). Moreover, for samples prepared at $T_{s} \geqslant 575^{\circ} \mathrm{C}$ we have detected the presence of As atoms in at least the first five layers showing the great sensitivity of low-temperature photoluminescence measurements.

One can note that we have deduced from PL measurements an InAs thickness higher than what was measured by XPS. This difference can be explained as follows: XPS cannot give a direct local measure of the lnAs thickness, but gives an evaluation of the number of arsenic atoms on the top layers. This number is obtained by analyzing the relative intensity of the As $3 d$ core level peaks. ${ }^{3}$ The number of InAs monolayers is then deduced by dividing the measured total number of As atoms by the number of As atoms assumed present in one perfect InAs monolayer. Suppose now that the InAs overlayers are not uniform (as occurs, when threedimensional islands are formed), the number of InAs ML determined by XPS measurements would be underestimated locally because it admits the existence of flat and homogeneous InAs layers. As a consequence, for samples annealed with $T_{\text {r }} \geqslant 570^{\circ} \mathrm{C}$ (In stabilized) during 2 min where PL measurements detect the presence of InAs layer with a thickness larger than that measured by XPS, we believe that the InAs layer probably forms three-dimensional islands of height up to $5 \mathrm{ML}$ and lateral extension of at least an exciton radius $(\sim 100 \AA)$. This is in agreement with RHEED measurements which indicate an InAs thickness of $6-10 \AA(\sim 2-3 \mathrm{ML})$ as being the onset of three-dimensional growth for growth temperatures greater than $525^{\circ} \mathrm{C} .^{16}$ For samples treated at high temperature. Gendry et al. argue that from a thermodynamical point of view the strained InAs layers prefer to form islands rather than be flat. ${ }^{17}$

For samples prepared at $T_{v}=450$ and $500^{\circ} \mathrm{C}$ where XPS measurements give an InAs thickness of 1.25 and 1.5 ML, respectively, PL has just detected the deep defect bands due to thermal degradation of the InP substrate. This means that the PL spectrum of these samples is identical to that of the reference (Fig. 2) and the etched samples (Fig. 3). The nonobservation of radiative transitions from InAs in these samples is mainly due to the small thickness of InAs layer, which would not confine enough carriers in the well to saturate the nonradiative transitions related to surface and interface states (as discussed above).

The observed transition energies have been compared to a theoretical calculation of the $E_{1} H_{1}$ transitions for a strained InAs quantum well embedded in $\operatorname{InP}$ barriers. We have solved the Schrödinger equation in a finite square well using both envelope function ${ }^{18}$ and effective mass approximation and including strain effects on the band structure and on the effective mass. Modification of the band structure due to strain was calculated using the three-band Kane model ${ }^{19}$ where the terms of $\epsilon \cdot k$ were neglected. ${ }^{20}$ The effective mass is given then by the dispersion relation near $k=0$. We have also taken into account the nonparabolicity of the bands. The conduction band offset used was $0.40 \mathrm{eV}$. We have used this value of $\Delta E_{c}$. because in previous work it has well fitted our results $^{11.21}$ and it also agrees with recent theoretical prevision $^{22}$ which takes into account the effect of strain on the InAs energy bands. Nevertheless, in the literature a large uncertainty in this value has been reported. Schneider and Wessels ${ }^{12}$ have compiled band offsets determined by different groups and techniques and have reported valence-band offset values between 0.27 and $0.48 \mathrm{eV}\left(\Delta E_{\mathrm{c}} \approx 0.50\right.$ and 0.70 $\mathrm{eV}$ ). However, for most of the values correction must be done because strain effects on the energy band structure are ignored. The resulting theoretical curve and the experimental points (Table II) are presented in Fig. 5. The general agreement is rather good even using a rectangular form of the potential. This form is not completely adequate to a surface quantum well due to the existence of surface states. These states can pin the Fermi level near the conduction band and bend the potential. ${ }^{23}$ Thus, a triangular potential form would better describe our surface quantum wells. Other sources of discrepancy could be (i) noninclusion of exciton binding energy in the calculation, (ii) a possible coupling between the confined states of the quantum wells with both surface and interface states, ${ }^{24}$ and (iii) the quality of the interfaces, with on the one hand, the possible formation at the interface of an InAs $\mathrm{P}_{1-x}$ graded layer due to some deep penetration of $\mathrm{As}$ atoms in the InP substrate, and on the other hand, the chemical and structural disorder of the oxide (vacuum)/InAs interface.

In Table II the values of the maximum energy and the linewidth of the fitted Gaussians are reported. Normally, in this kind of fit for emissions related to the same origins, the maximum energies and the linewidths of the Gaussians 


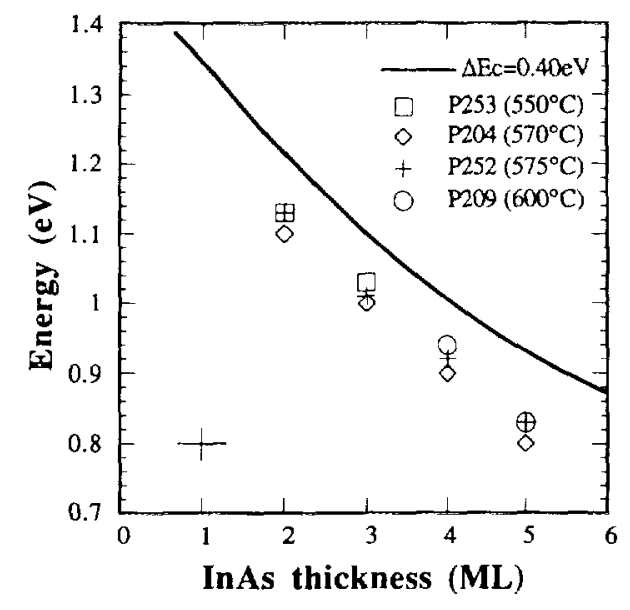

Fig. 5. Dependence of the photoluminescence emission energy with the In As layer thickness. The solid line is a theoretical calculation for strained InAs/InP square quantum wells using a conduction band offset of $0.40 \mathrm{eV}$. The cross on the bothum left side represents the error bar.

should be almost constants. We can observe that it happens only for the energy values. For the linewidths despite some fluctuation in the values, an anomalous behavior is observed. The large value of $205 \mathrm{meV}$ obtained for sample P204 for emission related to regions with $2 \mathrm{ML}$ is probably due to an overlapping of this emission with the $1.08 \mathrm{eV}$ deep defect band present in this sample as shown on the etched sample. The same argument can be used to explain the large linewidth of the $5 \mathrm{ML}$ related emissions for samples P252 and $\mathrm{P} 209$, but in this latter case overlapping is with the $0.85 \mathrm{eV}$ deep defect band

The PL linewidth $(\sigma)$ due to interface roughness, in a square well, is given by ${ }^{25}$

$$
\sigma=\left.\delta \frac{\partial E}{\partial W}\right|_{w_{0}},
$$

where $\delta$ is the two-dimensional island height, $E$ is the energy separation between electron and heavy-hole fundamental levels $\left(E_{1} H_{1}\right), W$ and $W_{0}$ being, respectively, the well size and the average size of the quantum wells. Using the calculation described above for the energy transition $E_{1} H_{1}$, we have derived, from relation (1) and with an interface roughness described by two-dimensional islands of one monolayer height $(\delta=1)$, PL linewidth values of 120 and $68 \mathrm{meV}$ for quantum well thicknesses of 2 and $5 \mathrm{ML}$, respectively. Comparing these theoretical results with those obtained by the fit (Table II), we can observe that there is not agreement (with exception for the $2 \mathrm{ML}$ emission), meaning that the interface in these samples cannot be described simply with a roughness of $1 \mathrm{ML}$. This is not surprising if we consider that for InAs layer with thickness greater than three monolayers, three-dimensional islands are formed rather than homogeneous and flat layers.

\section{CONCLUSION}

We have performed low-temperature photoluminescence to study the properties of InAs surface layers formed during the MBE arsenic stabilization process of InP substrates. We have examined samples prepared in the $450-600^{\circ} \mathrm{C}$ temperature range. Emissions from the InAs surface layer were clearly identified. These emissions disappear when the InAs surface layer is chemically etched and we only observe emissions from deep defects induced by thermal treatment. We have observed that as the stabilization temperature increases, the InAs layer due to the P-As exchange becomes thicker and thicker with a remarkable change in the As penetration depth when surface stabilization changes for As to In stabilization. The $\mathrm{P}-\mathrm{As}$ exchange process seems to stop for a thickness of $5 \mathrm{ML}$. This is a consequence of both the formation of an InAs layer which acts as a shield against further $P$ evaporation and the restoration of the structural order which would limit any other phosphorus exo-diffusion. For Instabilized surface $\left(T_{s} \geqslant 570^{\circ} \mathrm{C}\right)$ we have observed PL emissions from InAs layers thicker than those predicted by XPS. This was explained by the formation of three-dimensional islands. In order to better identify the PL transitions, we have fitted our spectra and compared the results with theoretical values. A good agreement has been obtained and the discrepancy observed is mainly due to the complex form of both potential and real interface.

\section{ACKNOWLEDGMENTS}

This work was supported in part by the European Economic Community under Esprit Basic Research Action No. 3086. One of us (A.T.) would like to thank CAPES for tinancial support.

IR. F. C. Farrow, J. Phys. D 8. L87 (1975).

${ }^{2} G$ J. Davies, R. Heckingbottom. H. Ohno. C. E. C. Wood, and A. R. Calawa, Appl. Phys. Lett. 37, $290(1980)$

${ }^{3}$ G. Hollinger. D. Gallet. M. Gendry. C. Santinelli, and P. Viktorovitch. J Vac. Sci. Technol. B 8, 832 (1990).

JJ. M. Moison. M. Bensoussan, and F. Houzay, Phys. Rev. B 34, 2018 (1986).

${ }^{5}$ G. Hollinger. R. Blanchet. M. Gendry. S. Santinelli. R. Skheyta, and $P$ Viktorovitch, J. Appl. Phys. 67, 4173 (1990).

"R. Blanchet. P. Viktorovitch, J. Chave, and C. Santinelli, Appl. Phys. Letl. 46. $761(1985)$.

${ }^{7}$ P. W. Yu. Solid State Commun. 34, 18.3 ( 1983 ).

${ }^{\mathrm{K}}$ H. Temkin. B. B. Dutt. W. A. Bonner. and V. G. Keramidas, J. Appl. Phys. 37. 7526 (1982).

${ }^{4}$ M. V. Rao, O. A Aina. A. Fathimulla. and P. E. Thompson, J. Appl. Phys. 64. 2426 (1988).

${ }^{10}$ E. H. Reihlen, D. Birkedal, T. Y. Wang, and G. B. Stringfellow, J. Appl. Phys. 68, 1750) (1990)

"Z. Sobiesierski, S. A. Clark, R. R. Williams, A. Tabata, T. Benyattou, G. Guillot, M. Gendry, G. Hollinger, and P. Viktorovitch. Appl. Phys. Lett. 58. 1863 (1991).

${ }^{12}$ R. P. Schneider and B. W. Wessels. Appl. Phys. Lett. 57. 1998 (1990)

G. Hollinger. M. Gendry, J. L. Duvault, C. Santinelli, P. Ferret, C. Miossi. and M. Pitaval. Appl. Surf. Sci. 56-58. 665 (1992)

${ }^{14}$ A. Herman. D. Bimberg, and J. Christen, J. Appl. Phys. 70, R1 (1991).

D. Bimberg. D. Mars, J. N. Miller. R. Bauer, and D. Oertel, J. Vac. Sci. Technol. B 4. 1014 (1986).

${ }^{16} \mathrm{M}$. Gendry, V. Druout. C. Santinelli, and G. Hollinger. Appl. Phys. Lett. 60. 2249 (1992).

${ }^{17} \mathrm{M}$. Gendry. V. Druout, C. Santinelli, G. Hollinger, C. Miossi, and M. Pitaval, J. Vac. Sci. Technol. B 10. 1829 (1992).

InG. Bastard and J. A. Brum, IEEE J. Quantum Electron. QE.22. 1625 $11986)$. 
"E. O. Kane. J. Phys Chem. Solids 1, 249 (1957)

20) J. Y. Marzin. Thesis. Université de Paris, 1987.

"H. Banvillet, E. Gil. A. M. Vasson, R. Cadoret, A. Tabata, T. Benyattou, and G. Guillot. Proc. SPIE 1361, 972 (1991).

YY. Foulon and C. Priester, Phys. Rev. B 45. 6259 (1992).
${ }^{23}$ R. M. Cohen, M. Kitamura, and Z. M. Fang, Appl. Phys. Lett. 50, 1675 (1987).

${ }^{24} \mathrm{~J}$. M. Moison, K. Elcess, F. Houzay, J. Y. Marzin, J. M. Gérard. F. Barthe, and M. Bensoussan, Phys. Rev. B 41, 12945 (1990).

${ }^{25}$ J. Singh and K. K. Bajaj. J. Appl. Phys. 57, 5433 (1985).

J. Vac. Sci. Technol. B, Vol. 12, No. 4, Jul/Aug 1994 